Print ISSN: 2233-4165 / Online ISSN: 2233-5382

doi:http://dx.doi.org/10.13106/ijidb.2018.vol9.no5.83.

\title{
Introduction and Activation Strategies for Smart Training of Corporate*
}

\author{
기업에서의 스마트 훈련 도입 및 활성화 방안 \\ Ji-Eun Lee $\left(\text { 이지은) }{ }^{* *} \text {, Sukjin Kwon (권숙진) }\right)^{* * *}$, Hyojung Jung (정효정)****
}

Received: April 14, 2018. Revised: May 2, 2018. Accepted: May 15, 2018.

\begin{abstract}
Purpose - The purpose of this study is to explore the introduction and activation of smart training for the effective training of vocational ability development of companies in the 4th industrial revolution era, we analyze the present status of smart training introduction and related difficulties and propose concrete activation plan.

Research design, data, and methodology - Through the online survey, we tried to confirm the recognition of corporate about smart training. Questionnaires include what are the benefits, expectations, and difficulties of smart training, etc. The survey was conducted from August 21, 2017 to September 4, 2017. A total of 69 companies participated in the questionnaire. The questionnaire results were analyzed through frequency analysis and contents analysis. Based on the results of the questionnaire, we found out the cause of inhibition of smart training activation and suggested activation strategies.

Results - The main reason for the provision of smart training is the expectation of the training performance and the recognition that it is possible to provide training in a flexible manner. The effectiveness of smart training operation was evaluated as a high level of contribution to the development of creative training course and the capacity of training institute. As a result of checking factors that hinders the activation of smart training, the most important reason is that the time and cost burden of the training institutes is excessive. The lack of expertise in the design of smart training courses and the burden of employers and trainees.

Conclusions - In order to activate smart training, it is necessary to find solutions to the obstacles at the internal or external level of training institutions. The internal barriers to the training organization are lack of internal competence for preparation and course management. In this regard, we need to consider providing consulting, best practices or guidance in the process of designing and operating smart training. On the other hand, as an external obstacle factor, it is necessary to provide incentives to participate in smart training. In addition, further research is needed on strategies that can lead to participation in smart training from the viewpoint of employers and learners.
\end{abstract}

Keywords: Corporate Education, Smart Training, Future Directions.

JEL Classifications: I21, I23, 125.

* This study was supported by the research grant of Ministry of Employment and Labor in 2017.

** First Author, Professor, Division of Management Information Systems, Hanyang Cyber University, Korea.

Tel: +82-2-2290-0430, E-mail: scully1215@hycu.ac.kr

*** Co-Author, Professor, Department of Early Childhood Education, Howon University, Korea.

Tel: +82-63-450-7437, E-mail: sjkwon@howon.ac.kr

**** Corresponding Author, Professor, School of General Education, Dankook University, Korea.

Tel: +82-31-8005-3972, E-mail: hyojung.jung@dankook.ac.kr

\section{1. 서론}

독일의 'Industry 4.0'에서 촉발되어 전 세계로 급속하게 확 산되고 있는 제4차 산업혁명은 일과 학습방식에 대한 근본적 인 변화를 요구하고 있다. 제4차 산업혁명의 핵심은 실제와 가상의 통합으로 사물을 자동적, 지능적으로 제어할 수 있는 가상물리 시스템(Cyber Physical System, CPS) 구축으로 인해 일하는 방식에도 큰 변화가 있을 것으로 예상되며 이에 대한 발 빠른 대응이 요구되고 있다. 보다 구체적으로는 기술과 인 간을 균형 있게 이해하는 하이테크, 하이터치(high-tech, hightouch) 직업이 증가할 것으로 예상됨에 따라 융복합적 역량을 갖춘 인재육성의 필요성이 대두되고 있으며, 지금까지 표준화 와 효율성에 집중해왔던 교육훈련은 비판적 사고력(critical 
thinking)과 창의력(creativity), 의사소통능력(communication Skills), 협업능력(collaboration)을 고루 갖춘 인재양성으로 방향 성을 바꿔 나가는 계기가 마련되고 있다.

이미 교육 선진국에서는 교육혁신을 통해 4차 산업혁명에 선도적으로 대응해나가고 있으며, 우리나라도 이러한 노력들이 이뤄지고 있다. 고용노동부는 제4차 산업혁명 대비 국가기술 자격을 개편하고 신기술 분야의 고급·융합인력 양성을 위한 사업을 추진하고 있으며, 교육부는 '지능정보사회에 대응한 중 장기 교육정책의 방향과 전략'을 발표하고 4차 산업혁명에 대 비한 공교육 혁신을 위해 미래사회형 인재양성을 위한 유연화, 자율화, 개별화, 전문화, 인간화라는 5 가지 키워드를 제시한 바 있다. 꼭 제4차 산업혁명이 아니더라도 사회는 교육훈련과 관련하여 과거와는 전혀 다른 패러다임을 주문하고 있다. 각종 학술연구와 $\mathrm{HR}$ 관련 국제 컨퍼런스에서는 학습자, 교수자, 콘 텐츠 상호간의 소통과 협력, 공유의 강조, ICT 기술을 통해 학 습을 수평적, 쌍방향적, 참여적, 지능적, 상호작용 방식으로 전 환, 기술요소와 학습요인의 결합, 실제적인 학습활동 지원 강 화를 주문하고 있다. 제4차 산업혁명의 핵심이 실재와 가상의 통합에 있듯이, 앞으로의 교육훈련도 온-오프의 경계를 허물고 기술과 교육훈련이 서로 연계되어야 하며 그러한 점에서 차별 화된 교수-학습 전략 및 기술요소를 활용해서 개인화 학습과 학습에 대한 높은 몰입을 촉진하는 스마트 훈련의 필요성이 증대될 것으로 예상되고 있다(Salehi, Zadeh, Saei, \& Rostami, 2013).

그러나 최근 기업교육 현장에서는 이러한 현장의 요구에 적 극적으로 대응하지 못하는 양상을 띠고 있다(Kim, 2017; Jung, 2017; Jung, 2018). 특히 고용보험 환급시장 내에서는 이러한 움직임이 아직은 부족한 것으로 보인다. 실제로 2016년 고용 기금 내에서 사업주 지원이 이뤄진 스마트 훈련의 경우 훈련 신청과 훈련실시 실적이 낮은 편이다. 최근 대학교육 및 기업 교육의 패러다임을 볼 때 스마트 훈련 도입의 필요성은 공유 되고 있지만, 스마트 훈련이 정부지원 제도 내에서 작동하는데 여러 가지 어려움이 존재함을 추측할 수 있다.

이에 본 연구에서는 4차 산업혁명 시대 기업의 효과적인 직 업능력개발 훈련을 위해 스마트 훈련의 도입 및 활성화를 촉 진하고자, 스마트 훈련 도입현황 및 관련 애로사항을 분석하 고, 구체적인 활성화 방안을 제안하고자 한다.

\section{2. 스마트 훈련의 개념과 현황}

\section{1. 스마트 훈련의 개념}

스마트 기술이 정보습득 및 활용방법에 영향을 미치고 스마 트 기술의 다양한 교육적 가능성이 논의되기 시작하면서 '스마 트 러닝', ‘스마트 훈련’이라는 개념이 사용되었다. 스마트 훈련 을 '스마트 기술에 기반을 둔 교육훈련'으로 인식되는 것이 보 편적이지만, 여러 연구자와 현장 전문가들은 '스마트'를 다양한 방식으로 개념화하고 있어, 스마트 훈련이란 무엇인가에 대하 여 정의를 내리는 것은 어렵다. 예를 들어, 스마트한 기술에 기반을 둔다는 의미에서의 스마트, 교육의 새로운 패러다임에 기반을 둔다는 관점에서의 스마트, 스마트한 상호작용을 지원 한다는 측면에서의 스마트 등이다(Choi, Woo, \& Jung, 2013). 이러한 정의들은 스마트 훈련이 어떠한 모습으로 구현되는가 혹은 스마트 훈련이 추구하는 교육훈련의 방향성이 무엇인가
에 따라 차별화된다. 다시 말해, 스마트 기기 활용, 지능적, 강 화된 실재감 등 스마트러닝이 추구하는 특성이 포함되는 것이 다.

‘스마트'의 사전적으로 ‘똑똑한', ‘영리한’의 의미를 내포하며 기존의 방식보다 좋다는 것을 의미한다. 이는 기존에 충족되지 않은 요구에 부응하고, 진화된 방식을 취한다는 의미로 해석할 수 있다. 현 시점에서 이러한 접근이 필요한 이유는 4차 산업 혁명 시대에 대한 적극적인 대응을 위하여 새롭게 대두되는 기술을 적극적으로 활용하는 한편, 애자일(Agile)과 같이 진화 하는 방식의 설계를 통해 학습자의 요구에 능동적으로 대응할 수 있어야 하기 때문이다. 다시 말해, 스마트 훈련은 기존의 원격훈련이 충족시키지 못한 부분을 충족시키고, 시장의 요구 를 반영하여 지속적으로 발전해나가는 훈련방식이다.

2016년 고용노동부에서는 기업에서의 교육훈련 트렌드와 인터넷원격훈련의 발전방향을 반영하여 스마트 훈련 제도를 도입하였다. 고용노동부에서는 스마트 훈련을 첨단기술을 교육 훈련에 활용하거나, 혁신적인 교수방법을 적용하여 훈련을 실 시하고, 온라인을 통해 훈련생을 관리하는 직업능력개발훈련으 로 정의하고 있다. 스마트 훈련은 기존의 인터넷원격훈련 및 혼합훈련 등에 비하여 첨단기술이나 혁신적인 훈련 방법을 통 하여 훈련의 성과를 증진시키는데 주안점을 두고 있다는 점이 특징이다.

첨단 기술의 예로는 가상현실(Virtual Reality), 증강현실 (Augmented Reality), 스마트 디바이스, 플랫폼 등이 있으며, 로봇, $\mathrm{Al}$ 등의 기술도 향후에는 추가될 가능성이 있다. 혁신적 인 훈련 방식 또한 다양하게 고려할 수 있는데, 온라인에서의 사전학습 후 오프라인 강의를 진행하는 플립러닝(Flipped Learning)이나 SNS를 기반으로 협업 학습을 진행하는 소셜 러 닝(Social Learning), 짧은 모듈식 콘텐츠 및 훈련이 이루어지 는 과정에서 학습자들의 요구를 반영하여 최적의 콘텐츠를 만 들어가는 진행형 과정(Progressive training), 훈련생 주도형 참 여훈련을 통한 프로젝트 학습 등이 스마트 훈련의 범주에 포 함될 수 있다.

스마트 훈련을 설계·개발하고 운영하기 위해서는 기존의 원 격훈련 및 집체훈련에 비해 많은 노력과 비용이 소요될 수 있 다. 이에 고용노동부는 스마트 훈련의 지원금을 인터넷원격훈 련 지원금을 보다 높게 책정하고 있으며, 직업능력심사평가원 에서는 적합성 심사를 통해 컨설팅을 제공하고, 스마트 훈련 개발 및 운영실적의 인증평가 연계 및 가점 부여 등 인센티브 를 강화함으로써 스마트 훈련 공급시장 확대와 훈련기관의 참 여를 유도하고 있다.

\section{2. 스마트 훈련 유형과 심의 기준}

\subsection{1. 스마트 훈련의 유형}

앞서 소개한 바와 같이 스마트 훈련은 크게 기술 기반 유형 과 교수설계 유형의 두 유형으로 구분할 수 있다. 기술 기반 유형은 새로운 IT 기술 활용 또는 스마트 디바이스의 기기 특 성을 반영하여 다양하고 창의적인 형태로 운영하는 원격훈련 유형을 의미하며, 교수설계 유형은 훈련의 효율성 및 효과성을 높이기 위해 특성화된 전략적 교수설계 방법을 사용하여 운영 하는 원격훈련 유형을 의미한다. 
$<$ Table 1> Types of Smart Training

\begin{tabular}{|c|l|}
\hline \multicolumn{2}{|c|}{ Technology-based Types } \\
\hline $\begin{array}{c}\text { Virtual } \\
\text { Reality } \\
\text { Utilization } \\
\text { Training }\end{array}$ & $\begin{array}{l}\text { A type of training that utilizes Virtual Reality } \\
\text { technology and implements it in a way similar } \\
\text { to actual training. }\end{array}$ \\
\hline $\begin{array}{c}\text { Augmented } \\
\text { Reality }\end{array}$ & $\begin{array}{l}\text { A type of training that allows trainees to } \\
\text { deliver more training content than the actual } \\
\text { environment by showing 3D virtual objects } \\
\text { Utilization } \\
\text { Training }\end{array}$ \\
\hline $\begin{array}{c}\text { Smart the real world. } \\
\text { Device }\end{array}$ & $\begin{array}{l}\text { A new type of technology-based training that } \\
\text { overcomes the limitations of existing remote } \\
\text { training by utilizing the characteristics of smart } \\
\text { devices. }\end{array}$ \\
\hline Training
\end{tabular}

이 외에도 스마트 훈련은 상당히 다양한 형태로 존재할 수 있으며, 지속적으로 진화할 수 있으나, 훈련기관의 이해를 돕 고 훈련성과를 담보하고자 정부는 <Table 1>과 같은 몇 가지 형태로 유형화하여 제시하고 있다.

\subsection{2. 스마트 훈련의 적합성 평가}

스마트 훈련은 기존 원격훈련과 정부 지원이 다른 만큼, 스 마트 훈련으로서의 기본 요건을 갖추고 있는지에 대한 심사과 정이 요구된다. 즉, 스마트 훈련으로써의 적합한지, 스마트 훈 련을 잘 운영할 수 있을지를 검토하는 과정이 필요하다. 정부 로부터 스마트 훈련으로 인정받아 과정을 진행하기 위해서는
사업주 직업능력개발 지원규정 최소요건을 준수해야 하며, 스 마트 훈련 심의를 통과해야 한다.

사업주 직업능력개발 지원규정 최소요건은 원격훈련의 최소 요건에 해당하는 부분이다. 현재 진행단계 평가를 실시하지 않 는 경우, 최종평가를 실시하지 않는 경우, 평가(시험, 과제 등) 문항이 3 배수가 되지 않는 경우(진행단계 평가 제외), 평가 성 적이 60점 이하인 경우(100점 만점 기준), 과정인정요건 중 LMS 학사관리시스템 항목을 갖추지 못한 경우, 집체활동 포 함하는 과정에서 집체의 출결 및 훈련생관리가 웹상에서 연동 될 수 있는 기능이 갖춰지지 않은 경우는 부적합으로 판정된 다.

해당 요건을 통과한 이후에는 5 명 전후로 구성된 스마트 훈 련 심의위원회를 통해 적합성을 검증받게 되는데, 심의 위원들 은 크게 기관운영역량과 과정설계 및 운영 적정성을 검토하며, 훈련기관의 역량(훈련 능력과 정상적 기관운영 여부)을 토대로 가점이나 감점을 부여할 수 있다. 이 과정을 통해 스마트 훈련 으로 인정받으면 그 다음 단계인 내용심사를 거치게 된다. 스 마트 훈련 심의 기준은 기관운영 역량, 과정설계 및 운영 적정 성, 가점 및 감점 요소로 구분된다.

\subsection{3. 스마트 훈련의 사례}

국내에서 스마트 훈련을 도입한 대표적인 사례를 살펴보면 다음과 같다. 『마이스터에게 배우는 강관 제조기술 노하우』 과 정은 교강사-학습자 간, 학습자 간 상호작용을 통해 실시간 업 데이트되는 진행형 콘텐츠이다. 해당 과정의 스마트 요소는 첫 째, 교강사-학습자 상호작용을 통해 지속적으로 콘텐츠를 업데 이트함으로써 멀티미디어 북 진행형 콘텐츠를 구현했다는 점, 둘째, 전문 교강사를 통한 지속적인 맞춤형 피드백 및 $1: 1$ 사 후클리닉을 지원함으로써 개인화된 경험을 제공했다는 점, 셋 째, 스마트 기기 지원을 통한 적시학습 및 실시간 학습관리를 지원했다는 점을 꼽을 수 있다.

『Fundamental Sales Course $\mathrm{FSC}_{\rrbracket}$ 과정은 플립러닝의 전 형적인 과정이다. 과정 구성은 원격훈련을 통해 18시간 동안 사전학습을 실시하고, 이후 8시간 동안 집체훈련을 통해 본 학습을 하는 구조로, 온라인에서 사전 진단 및 기본원리를 학 습한 후 오프라인에서 개별 코칭이 이뤄지는 방식으로 훈련이 운영되었다. 온라인과 오프라인이 연계되도록 학습자 활동이 설계되었고, 목표 학습자의 특성을 잘 반영하고 있다. 해당 과 정의 주요 대상자는 영업사원으로, 이들의 직무 특성을 고려하 여 여유시간을 이용해서 이러닝을 학습하고, 하루 동안 실전학 습을 하여 시간적 부담감을 최소화하면서 훈련 성과는 극대화 할 수 있다는 이점이 기대된다.

『소셜 학습으로 살펴보는 매장 진열기법』과정은 진행형 과 정으로 인터넷원격훈련과 소셜 활동을 각각 8시간 배정하여 총 16 시간짜리 과정으로 기획되었다. 교육대상자는 마트 종사 자로, 인터넷원격훈련을 통해 매장 진열방법을 익히고, 매장에 서 배운 내용을 제품 진열에 적용하도록 하고, 진열 결과(실무 적용)를 사진으로 공유하고 교강사나 훈련생들이 그에 대한 평가 의견을 올리도록 과정이 설계되었다. 본 과정은 맞춤형 훈련에 따른 훈련성과를 강화하고 학습자의 소셜 활동을 통해 양질의 콘텐츠를 생산할 수 있다는 점에서 스마트한 훈련과정 으로 평가되었다. 


\section{3. 연구방법}

\section{1. 설문 내용 및 분석 방법}

본 연구의 목적은 스마트 훈련 도입 및 활성화를 위한 방안 을 탐색하는 것이다. 이를 위하여 설문을 통하여 훈련기관 및 사업주단체의 인식을 확인하고자 하였다. 훈련기관 및 사업주 단체 대상의 온라인 설문을 통하여 스마트 훈련의 특장점과 기대효과 및 애로사항이 무엇인지 확인하였으며, 혼합훈련 및 스마트 훈련의 저변 확대와 성과 확산을 위한 의견을 물음으 로써 시사점을 도출하고자 하였다.

$<$ Table 2> Composition of the survey

\begin{tabular}{|c|c|}
\hline Survey Question & Subject \\
\hline $\begin{array}{l}\text { Training organization information (year of } \\
\text { establishment, size of institution, type of } \\
\text { training facility, ratio of major related to } \\
\text { education, type of training provided in the } \\
\text { last three years, etc.) } \\
\text { - Understanding of Smart Training }\end{array}$ & all \\
\hline $\begin{array}{l}\text { The biggest reason to supply smart training } \\
\text { - Effects through smart training } \\
\text { - Smart training supply expansion plan }\end{array}$ & El, QI, PI \\
\hline $\begin{array}{l}\text { Awareness of need for smart training supply } \\
\text { Why not provide smart training } \\
\text { Smart training operation plan(If the smart } \\
\text { training market is expanded) }\end{array}$ & IN \\
\hline $\begin{array}{l}\text { Promotion of new type of training supply of } \\
\text { smart training } \\
\text { The effect of supplementing the limitation of } \\
\text { existing remote training of smart training } \\
\text { - Possibility of future smart training } \\
\text { Factors impeding the activation of smart } \\
\text { training } \\
\text { - Efforts to promote smart training } \\
\text { - Recognition of collective, remote, and mixed } \\
\text { training }\end{array}$ & all \\
\hline
\end{tabular}

온라인 설문지를 만들어 파일럿 테스트를 실시한 후, 훈련 기관 담당자에게 메일을 통해 전달하였다. 동일인의 중복 참가 를 막기 위해 동일 IP에서는 2회 이상 응답하지 못하도록 설 문조사 시스템을 설계하였으며, 전체 항목 중 하나라도 응답하 지 않을 경우 설문이 완료되지 못하도록 하였다. 설문조사는 2017년 8월 21일부터 9월 4일까지 이루어졌으며, 응답이 수거 된 시점에서 조사를 종료하고 통계 분석을 실시하였다. 총 69 개 기업의 훈련 담당자가 설문에 참여하였으며, 스마트 훈련 운영경험이 있는 기업(El: Experienced Institutions), 스마트 훈 련 과정심사를 통과한 기업(QI: Qualified Institutions), 스마트 훈련 도입을 계획하고 있는 기업(PI: Preparing Institutions), 스 마트 훈련 도입 계획이 없는 기업(IN: Institutions that has no plan)을 구분하여 설문을 진행하였다. 설문 결과는 빈도 분석 및 내용 분석(Content analysis)을 통해 설문 결과를 분석하였 다. 설문 결과를 토대로 스마트 훈련 활성화 저해원인을 도출 하였으며, 활성화 방안에 대한 구체적인 내용을 제안하였다.

\section{2. 연구 대상}

설문에 참여한 기관의 설립년도, 기관 규모(상시 종업원 수), 훈련시설 유형, $\mathrm{HRD}$ 교육학·교육공학 전공자 비율은 $<$ Table $3>$ 에 나타난 바와 같다.

$<$ Table $3>$ Characteristics of participating institutions

\begin{tabular}{|c|c|c|c|}
\hline \multicolumn{2}{|r|}{ Division } & \multicolumn{2}{|c|}{ Frequency } \\
\hline \multirow{4}{*}{$\begin{array}{c}\text { Established } \\
\text { Year }\end{array}$} & Less than 3 years & 16 & $23.2 \%$ \\
\hline & $3 \sim 5$ years & 8 & $11.6 \%$ \\
\hline & $5 \sim 10$ years & 20 & $29.0 \%$ \\
\hline & More than 10 years & 25 & $36.2 \%$ \\
\hline \multirow{4}{*}{$\begin{array}{l}\text { Number of } \\
\text { employees }\end{array}$} & Less than 20 & 32 & $46.4 \%$ \\
\hline & $20 \sim 50$ & 12 & $17.4 \%$ \\
\hline & $50 \sim 100$ & 14 & $20.3 \%$ \\
\hline & More than 100 & 11 & $15.9 \%$ \\
\hline \multirow{4}{*}{$\begin{array}{c}\text { Type of } \\
\text { Institution }\end{array}$} & Business group etc. & 7 & $10.1 \%$ \\
\hline & Vocational Education & 23 & $33.3 \%$ \\
\hline & Higher Education & 3 & $4.3 \%$ \\
\hline & Lifelong Education & 36 & $52.2 \%$ \\
\hline \multirow{4}{*}{$\begin{array}{c}\text { Ratio of } \\
\text { majors }\end{array}$} & $0 \%$ & 4 & $5.8 \%$ \\
\hline & $\sim 20 \%$ & 36 & $52.2 \%$ \\
\hline & $20 \%$ to less than $50 \%$ & 13 & $18.8 \%$ \\
\hline & More than $50 \%$ & 16 & $23.2 \%$ \\
\hline \multicolumn{2}{|r|}{ Sum } & 69 & $100 \%$ \\
\hline
\end{tabular}

$<$ Table 4> Characteristics of survey participating institutions (type of training provided in the last 3 years)

\begin{tabular}{|c|c|c|r|}
\hline \multicolumn{2}{|c|}{ Division } & \multicolumn{2}{c|}{ Frequency } \\
\hline \multirow{2}{*}{\begin{tabular}{c} 
A recent type of \\
training provided \\
for 3 years \\
\cline { 2 - 4 } (Select all)
\end{tabular}} & On-line training & 63 & $91.3 \%$ \\
\cline { 2 - 4 } & Smart training & 10 & $14.5 \%$ \\
\cline { 2 - 4 } & Off-line training & 16 & $23.2 \%$ \\
\cline { 2 - 4 } & Postal training & 17 & $24.6 \%$ \\
\hline
\end{tabular}

또한 <Table 4>에 제시된 바와 같이 최근 3 년 간 제공한 훈련 유형으로는 인터넷 원격훈련이 가장 높은 비중을 차지하 였으며, 우편원격훈련, 집체훈련이 다음 순위로 나타났다.

\section{4. 연구 결과}

\section{1. 스마트 훈련 운영경험 및 이해도}

스마트 훈련 운영경험 여부를 조사한 결과 <Table 5>에 나 타난 바와 같이 운영 경험이 있는 기관은 7 개 기관(10.1\%)에 해당하였고, 심사 통과 기관은 5 개 기관( $7.2 \%)$, 과정 준비 기 관은 23 개(33.3\%), 과정 운영 계획이 없다고 응답한 기관은 
34개로 $49.3 \%$ 이었다 $(<$ Table $5>)$.

$<$ Table 5> Characteristics of survey participating institutions (Smart training operation experience)

\begin{tabular}{|c|c|r|}
\hline Division & \multicolumn{2}{|c|}{ Frequency } \\
\hline Experienced Institutions & 7 & $10.1 \%$ \\
\hline Qualified Institutions & 5 & $7.2 \%$ \\
\hline Preparing Institutions & 23 & $33.3 \%$ \\
\hline Institutions that has no plan & 34 & $49.3 \%$ \\
\hline Sum & 69 & $100.0 \%$ \\
\hline
\end{tabular}

훈련유형 별 기관의 확보 수준을 담당 인력 전문성, 킬러 콘텐츠 공급 능력, 시설 및 장비 수준, 제도에 대한 이해 수준 을 토대로 확인한 결과, 담당인력의 전문성, 킬러콘텐츠 공급 능력, 훈련에 필요한 시설·장비 확보 수준은 원격-집체-스마트 훈련의 순으로 나타났으며, 제도에 대한 이해 수준은 원격-집 체-스마트 순으로 나타나, 스마트 훈련 관련 인프라 확보 수준 이 낮고, 해당 제도에 대한 이해도도 낮은 상황임을 알 수 있 다 $(<$ Table 6>).

<Table 6> Characteristics of survey participating institutions (level of institutionalization by type of training)

\begin{tabular}{|c|c|c|c|}
\hline Division & $\begin{array}{c}\text { Off-line } \\
\text { training }\end{array}$ & $\begin{array}{c}\text { On-line } \\
\text { training }\end{array}$ & $\begin{array}{c}\text { Smart } \\
\text { training }\end{array}$ \\
\hline $\begin{array}{c}\text { Expertise of } \\
\text { manpower }\end{array}$ & $3.09(1.234)$ & $4.14(0.879)$ & $2.8(1.092)$ \\
\hline $\begin{array}{c}\text { Ability to supply } \\
\text { killer content }\end{array}$ & $3.14(1.298)$ & $4.04(0.962)$ & $2.75(1.156)$ \\
\hline $\begin{array}{c}\text { Level of facility } \\
\text { and equipment } \\
\text { securing }\end{array}$ & $2.94(1.235)$ & $4.17(0.939)$ & $2.86(1.228)$ \\
\hline $\begin{array}{c}\text { Understanding } \\
\text { of the system }\end{array}$ & $3.33(1.159)$ & $4.14(0.959)$ & $3.01(1.131)$ \\
\hline Average & $3.13(1.232)$ & $4.12(0.935)$ & $2.86(1.152)$ \\
\hline
\end{tabular}

스마트 훈련에 대한 이해도는 스마트 훈련 과정심사 통과 기관이 가장 높았고, 운영경험 기관과 과정 준비기관, 운영계 획이 없는 기관 순으로 나타났다(<Table 7>)

$<$ Table 7> Understanding of smart training according to smart training operation experience

\begin{tabular}{|c|c|c|}
\hline Division & N & $\begin{array}{c}\text { Understanding of } \\
\text { Smart Training }\end{array}$ \\
\hline Experienced Institutions & 7 & $3.57(1.397)$ \\
\hline Qualified Institutions & 5 & $4.40(0.548)$ \\
\hline Preparing Institutions & 23 & $3.57(0.728)$ \\
\hline Institutions that has no plan & 34 & $3.06(0.886)$ \\
\hline Average & 69 & $3.38(0.941)$ \\
\hline
\end{tabular}

\section{2. 스마트 훈련 공급 이유와 성과}

스마트 훈련을 공급하게 된 가장 큰 이유는 훈련 성과에 대 한 기대와 유연한 방식으로 훈련제공이 가능하다는 인식인 것
으로 나타났다. 사업주 및 학습자의 요구, 과정 홍보 효과 및 정부 정책에의 동참 또한 어느 정도 영향을 미친 것으로 나타 났다. 기타 이유로는 '시범 사업 참여'가 있었다(<Table 8>).

$<$ Table 8> Reasons for Supply of Smart Training

\begin{tabular}{|c|c|r|}
\hline Division & \multicolumn{2}{|c|}{ Frequency } \\
\hline Training achievement & 17 & $27.0 \%$ \\
\hline Flexible training available & 16 & $25.4 \%$ \\
\hline Existence of employers and learners & 10 & $15.9 \%$ \\
\hline $\begin{array}{c}\text { Institutional merit such as process } \\
\text { publicity effect }\end{array}$ & 5 & $7.9 \%$ \\
\hline To participate in government policy & 5 & $7.9 \%$ \\
\hline Monetization potential & 3 & $4.8 \%$ \\
\hline Etc. & 7 & $11.1 \%$ \\
\hline Sum & 63 & $100.0 \%$ \\
\hline
\end{tabular}

스마트 훈련의 성과를 무엇으로 보는가에 대한 질문에 스마 트 훈련에 대한 고객사(사업주, 교육담당)의 관심도, 학습자의 관심도는 보통 수준인 것으로 나타났지만, 학습자의 만족도는 만족스러운 수준인 것으로 나타났다. 이는 스마트 훈련에 참여 하기 전에는 새로운 훈련방식에 대한 관심이 없었지만, 경험한 이후에 해당 훈련 방식에 대한 만족도가 높아졌음을 시사한다. 스마트 훈련 운영이 훈련기관 차원에서의 성과로써 창의적 훈련과정 개발 효과 및 훈련기관 내부역량 강화에 기여하는 정도는 높은 수준이라고 평가하는 반면, 재무적 성과나 기관위 상 제고 효과는 보통 수준으로 평가하고 있었다(<Table 9>).

$<$ Table 9> Internal \& External Performance of Smart Training

\begin{tabular}{|c|c|}
\hline Division & $\mathbf{M ( S D )}$ \\
\hline $\begin{array}{c}\text { The interest of customers } \\
\text { (Employer, Institution) }\end{array}$ & $3.15(1.028)$ \\
\hline Learner's interest & $3.01(1.002)$ \\
\hline Learner's satisfaction & $3.90(0.995)$ \\
\hline Development of creative training course & $3.84(0.937)$ \\
\hline Financial performance & $3.27(0.998)$ \\
\hline $\begin{array}{c}\text { Capacity enhancement within the training } \\
\text { institution }\end{array}$ & $4.03(0.688)$ \\
\hline Better recognition of institutions & $3.77(0.817)$ \\
\hline Customer satisfaction enhancement & $3.92(0.871)$ \\
\hline
\end{tabular}

\section{3. 스마트 훈련의 잠재력}

스마트 훈련이 새로운 형태의 훈련공급을 촉진하는지, 기존 원격훈련의 한계를 보완하는지에 대하여 전반적으로는 보통 수준으로 인식하고 있었으나, 기존 원격훈련의 한계를 보완하 는 효과에 대하여 보다 긍정적으로 응답하였다. 특히 스마트 훈련 운영경험이 있는 기업의 경우 스마트 훈련이 기존 원격 훈련의 한계를 보완할 수 있다고 인식하고 있는 것으로 나타 났다. 스마트 훈련이 확산될 가능성에 대해서는 평균적으로 보 통 수준으로 응답하였으나, 스마트 훈련 운영경험 기업의 경우 에는 다른 기업에 비하여 보다 긍정적으로 응답하였다. 
$<$ Table 10> The potential of smart training

\begin{tabular}{|c|c|c|}
\hline Division & $\begin{array}{c}\text { Promote new forms } \\
\text { of training supply }\end{array}$ & $\begin{array}{c}\text { Complementing the limits } \\
\text { of traditional training }\end{array}$ \\
\hline $\begin{array}{c}\mathrm{El} \\
(\mathrm{N}=7)\end{array}$ & $3.57(1.512)$ & $4.00(1.414)$ \\
\hline $\begin{array}{c}\mathrm{Ql} \\
(\mathrm{N}=5)\end{array}$ & $3.40(0.548)$ & $3.60(0.548)$ \\
\hline $\begin{array}{c}\mathrm{Pl} \\
(\mathrm{N}=23)\end{array}$ & $3.57(1.037)$ & $3.83(0.984)$ \\
\hline $\begin{array}{c}\mathrm{IN} \\
(\mathrm{n}=34)\end{array}$ & $3.41(1.131)$ & $3.41(1.158)$ \\
\hline Average & $3.48(1.093)$ & $3.62(1.099)$ \\
\hline
\end{tabular}

\section{4. 스마트 훈련 공급확대 계획}

스마트 훈련을 준비하거나 참여한 경험이 있는 기업을 중심 으로 스마트 훈련 공급확대 계획에 대해 확인한 결과, 검토 중 이나 뚜렷한 계획은 없다는 응답과 점차 확대할 예정이라는 응답이 많았다.

$<$ Table 11> Smart training supply expansion plan

\begin{tabular}{|c|c|c|c|r|}
\hline Division & $\begin{array}{c}\text { EI } \\
\mathbf{( N = 7 )}\end{array}$ & $\begin{array}{c}\text { QI } \\
\mathbf{( N = 5 )}\end{array}$ & $\begin{array}{c}\text { PI } \\
\mathbf{( N = 2 3 )}\end{array}$ & Frequency \\
\hline $\begin{array}{c}\text { No expansion } \\
\text { plans at all }\end{array}$ & 1 & & & $1(2.9 \%)$ \\
\hline $\begin{array}{c}\text { No review or } \\
\text { clear plans }\end{array}$ & 2 & 1 & 14 & $17(48.6 \%)$ \\
\hline $\begin{array}{c}\text { Plan to expand } \\
\text { gradually }\end{array}$ & 3 & 4 & 9 & $16(45.7 \%)$ \\
\hline $\begin{array}{c}\text { Plan to enlarge } \\
\text { front }\end{array}$ & 1 & & & $1(2.9 \%)$ \\
\hline Sum & 7 & 5 & 23 & $35(100.0 \%)$ \\
\hline
\end{tabular}

스마트 훈련 공급에 대한 필요성 인식 정도, 스마트 훈련 시장이 확대될 경우, 훈련공급 의도를 확인한 결과 모두 보통 수준인 것으로 나타났다.

$<$ Table 12> Smart training need recognition and training Intent to supply

\begin{tabular}{|c|c|}
\hline Division & $\mathbf{M ( S D )}$ \\
\hline Need recognition & $3.12(0.913)$ \\
\hline $\begin{array}{c}\text { Smart training operation plan(If the smart } \\
\text { training market is expanded) }\end{array}$ & $3.41(0.957)$ \\
\hline
\end{tabular}

\section{5. 스마트 훈련 도입 장애요소}

스마트 훈련 도입에 걸림돌이 되는 장애요소가 무엇인지 확 인하기 위하여 스마트 훈련을 공급하지 않는 이유에 대하여 확인하였다.

설문 결과, 우선 사업주 및 학습자의 요구가 없다는 의견이 가장 높게 나타났다. 즉, 스마트 훈련에 대한 시장의 요구를 확인하기 어렵다는 점이 일차적인 이유로 나타났는데, 이는 스 마트 훈련에 대한 시장의 인식 및 이해가 부족하기 때문으로 해석된다. 또한 유연한 방식으로 훈련제공이 어렵다는 점, 내 부 역량 부족, 과정 심사에 대한 부담감, 수익창출이 어렵다는
점 또한 높은 비중을 차지하였다. 다음 순위로는 기업에게 별 다른 메리트가 없다는 의견이 뒤따랐다(<Table 13>).

$<$ Table 13> Smart training introduction obstacle factor

$(n=35)$

\begin{tabular}{|c|c|r|}
\hline Division & \multicolumn{2}{|c|}{ Frequency } \\
\hline No need for employers and learners & 15 & $25.0 \%$ \\
\hline Difficult to provide training in a flexible manner & 10 & $16.7 \%$ \\
\hline Insufficient internal capacity & 9 & $15.0 \%$ \\
\hline Low monetization potential & 8 & $13.3 \%$ \\
\hline Burden of course review & 8 & $13.3 \%$ \\
\hline There is no merit for the institution & 5 & $8.3 \%$ \\
\hline $\begin{array}{c}\text { The training results are not expected to be } \\
\text { significant }\end{array}$ & 3 & $5.0 \%$ \\
\hline Etc. & 2 & $3.3 \%$ \\
\hline Sum & 60 & $100.0 \%$ \\
\hline
\end{tabular}

스마트 훈련의 활성화를 저해하는 요인에 대한 확인 결과, 훈련기관의 시간적·비용적 부담이 과중하다는 점을 가장 큰 이 유로 꼽았으며, 스마트 훈련 과정설계에 대한 전문성 부족 및 훈련참여에 따른 사업주·훈련생 부담이 과다하다는 점을 주요 이유로 꼽았다 $(<$ Table 14>).

$<$ Table 14> Smart training inhibition factor (Option 2)

\begin{tabular}{|c|c|c|}
\hline Division & Fre & quency \\
\hline Over time and cost burden of training institutions & 52 & $39.40 \%$ \\
\hline Lack of expertise in smart training course design & 28 & $21.20 \%$ \\
\hline $\begin{array}{l}\text { Excessive burden on employers and trainees } \\
\text { due to training participation }\end{array}$ & 23 & $17.40 \%$ \\
\hline $\begin{array}{l}\text { Inadequate publicity for institutional and training } \\
\text { courses }\end{array}$ & 7 & $5.30 \%$ \\
\hline Lack of governmental institutional support & 7 & $5.30 \%$ \\
\hline $\begin{array}{l}\text { The conceptual definition of smart training is } \\
\text { ambiguous }\end{array}$ & 7 & $5.30 \%$ \\
\hline $\begin{array}{l}\text { Lack of understanding of training institutions on } \\
\text { the system }\end{array}$ & 5 & $3.80 \%$ \\
\hline Etc. & 3 & $2.30 \%$ \\
\hline Sum & 132 & $100.0 \%$ \\
\hline
\end{tabular}

스마트 훈련의 활성화를 위하여 향후 필요한 노력으로는 과 정설계·운영·평가의 자율성을 최대한 인정할 것, 심사과정의 간소화를 가장 우선순위로 꼽았다. 이와 더불어 비용인정 폭의 확대와 스마트 훈련 기획 관련 컨설팅 제공, 스마트 훈련 성공 사례의 확보 및 홍보 또한 높은 순위로 나타났다(<Table 15>).

$<$ Table 15> Efforts to activate smart training (Option 2)

\begin{tabular}{|c|r|r|}
\hline Division & \multicolumn{2}{|c|}{ Frequency } \\
\hline Recognizing the autonomy of the institution & 30 & $22.20 \%$ \\
\hline Simplify the screening process & 27 & $20.00 \%$ \\
\hline Expansion of cost recognition(200\% $\rightarrow 300 \%)$ & 19 & $14.10 \%$ \\
\hline Consulting offer & 17 & $12.60 \%$ \\
\hline Gain Success Stories & 14 & $10.40 \%$ \\
\hline Expansion of choice & 12 & $8.90 \%$ \\
\hline Strengthen PR & 9 & $6.70 \%$ \\
\hline Significantly mitigate requirements & 5 & $3.70 \%$ \\
\hline Etc. & 2 & $1.50 \%$ \\
\hline Sum & 135 & $100.0 \%$ \\
\hline
\end{tabular}


4.6. 스마트 훈련 활성화를 위한 제언

스마트 훈련 활성화를 위하여 요구되는 것은 무엇인가에 대 하여 확인하기 위하여 개방형 질문 방식으로 의견을 수렴하였 다. 응답 결과는 다섯 가지 의견으로 분류할 수 있는데, 세부 적인 내용과 관련 의견은 다음에 제시된 바와 같다.

첫 번째 의견은 스마트훈련의 정의 및 제도에 대한 이해가 부족하고 기업들이 움직일만한 유인책이 없다는 의견이었다. 기본적으로 스마트 훈련의 개념이 기업훈련의 관련 주체들에 게 충분하게 공유되지 못하고 있는 상황이며, 스마트 훈련과 기존의 훈련과의 차별성이 인식되지 못하고 있음을 지적하고 있다. 또한 스마트 훈련의 실제적인 가치가 무엇인가에 대해서 도 공유될 필요가 있음을 강조하였다. 이에 대한 훈련 담당자 들의 의견은 다음과 같다.

어떤 과정이 스마트훈련으로 인정되는지, 심사를 위해 어떤 준비가 필요한지를 기업에서 잘 모르는 경우가 많다. 주무부처 에서 열심히 홍보를 하고 있지만, 정작 훈련기관에서는 수익성 이나 채산성 문제로 별다른 관심을 가지지 않는다. 스마트 훈 련의 개념정의 및 대상교육에 대한 세부적인 안내와 심사절차 안내가 필요하다. 어떤 과정까지 스마트 훈련으로 인정이 되는 지, 심사에는 어떤 준비가 필요한지에 대한 상세한 안내가 선 행되어야 한다(훈련 담당자 $\mathrm{A}$ ).

스마트 훈련이 뭔지를 잘 모르고, 우리 분야에서 잘나가는 기업들도 스마트 훈련 학생 모집에 고전하고 있다는 애기를 들은 바 있다. 시장이 있고 인기가 있고 비즈니스적 가치가 있 다는 인식이 확산되어야 기업이 움직일 텐데 아직은 시장에서 그런 시그널이 없다. 어떤 훈련이 스마트 훈련인지, 스마트 훈 련의 가치가 무엇인지 확인할 수 있는 증거가 있었으면 한다 (훈련 담당자 $\mathrm{B}$ ).

두 번째 의견으로는 스마트 훈련을 도입하고자 하는 기업에 대한 컨설팅을 지원할 필요가 있으며, 스마트 훈련과정 심사 단계의 간소화가 요구된다는 의견이 있었다. 스마트 훈련은 기 본적으로 기존의 방식과는 달리 새로운 기술 혹은 설계적 접 근이 필요하므로 진입장벽을 낮추기 위한 노력이 필요하다는 것이다. 구체적인 내용은 다음과 같다.

시대가 빠르게 변화하고, 그에 대한 과정개발이 빠르게 바 뀌어야 하는데, 스마트 훈련과정개발에 드는 비용이 크기 때문 에 작은 교육기관에서 스마트 훈련을 도입하는 것은 어렵다 (훈련 담당자 $\mathrm{C}$ ).

스마트 훈련이 큰 수익을 가져올 수 있을지 명확하지 않은 상태에서, 심사 대비하는 노력과 시간에 비하여 부적합 판정을 받을 경우 내부에서는 오픈일이 몇 개월 연장되는 등 위험요 소가 큰 편이다. 부적합 받을 경우 보완하여 재심사할 경우에 는 심사결과를 조금 더 빠르게 알려주거나, 심사 제도를 완화 하거나, 혹은 스마트 훈련에 한해서는 프로모션을 가능하게 하 는 등 수익성 측면에서 훈련기관이 공격적으로 도전하고 의사 결정할 수 있는 요소가 있었으면 좋겠다(훈련 담당자 D).

세 번째 의견으로는 스마트 훈련의 설계·개발·운영을 위한 연구, 투자를 위한 지원할 필요가 있다는 제안이 있었다. 스마 트 훈련의 실제적인 도입 방법, 발전 방향에 대한 충분한 고민
이 이루어지고, 진화하고 숙성시켜 나갈 수 있는 여건을 마련 해야만 스마트 훈련이 보다 실효성 있는 방식으로 도입될 수 있을 것이라는 것이다. 이와 관련된 세부적인 의견은 다음에 제시된 바와 같다.

혁신적인 시도에는 연구와 투자하는 시간이 필요하다. 이를 위해 처음에 시범사업 등을 열어 준다면 기본 투자를 바탕으 로 사업을 시작할 수 있는 원동력이 될 수 있을 것이다(훈련 담당자 $\mathrm{E})$.

장기적인 계획을 세워서 단계별로 접근이 필요하다. 1차년 도 표준화된 플랫폼을 무료로 보급, 2차년도 플랫폼에 맞는 콘텐츠를 육성, 3차년도 다양한 의견을 수렴하여 플랫폼을 업 그레이드, 4차년도 육성된 콘텐츠를 중심으로 확대 연계할 수 있는 콘텐츠 육성, 5차년도 플랫폼 기술을 완전히 민간 이양 하는 방식으로 추진한다면 좋겠다(훈련 담당자 F).

네 번째 의견으로는 개발·운영방식의 유연성 확보가 요구된 다는 점이 강조되었다. 스마트 훈련의 유인책으로는 스마트 훈 련에 대한 지원금 등의 인센티브가 고려되고 있는데, 보다 다 양한 방식의 스마트 훈련이 시도될 수 있도록 보다 유연한 방 식과 체제를 허용하는 방안이 고려되어야 한다는 것이다. 상세 한 내용은 다음과 같다.

비용 인정 폭을 높이기보단 다양한 방식을 수용할 수 있도 록, 개발 형태에 따라 인정 폭이 탄력적으로 적용되어야 한다 고 생각한다. 또한 스마트 훈련도 개발형태에 따라 적합조건이 낮아질 수도 있어야 한다고 생각한다. 접근성이 가볍고 편리한 스마트 훈련과 접근성이 떨어지지만 고차원적인 학습방식을 취하는 스마트 훈련이 있어야 요구조건에만 맞추는 획일화된 개발 방식에서 탈피할 수 있다. 기존의 정형화된 방식을 탈피 한 다양한 학습활동을 구성할 수 있도록 강의, 시험, 과제 등 구성필수 학습활동의 제약이 없었으면 한다(훈련 담당자 $\mathrm{G}$ ).

훈련기관의 스마트 훈련 준비, 제작에서 심사, 인정까지의 기간이 오래 걸려 즉시 요구를 반영하기 어렵다. 훈련 분량이 나 공급방식에의 유연성 확보가 관건이다(훈련 담당자 $\mathrm{H}$ ).

스마트 훈련 과정 설계 및 심사에 있어서, 기업 입장에서 더 수월하고 편하게 접근할 수 있도록 개선이 요구된다. 구체 적으로 1) 스마트 훈련 교육상품의 절대 개수가 증가하여 상 품 라인업이 될 때까지 교육기관의 자발적 공급확대(상품개발) 유인책을 제공할 필요가 있다. 또한 2) 고객사에 요구에 따라 유연하게 콘텐츠를 수정·보완할 수 있는 변경제도를 마련해야 하며, 3) 중소기업 핵심직무 교육수요를 스마트 훈련으로 흡수 하는 제도적 방안을 모색하고, 4) 집합-원격교육 기관평가 평 가기준에 스마트 훈련 관련 실적(개발, 운영) 가산점을 확대하 는 방안 등을 고려했으면 한다(훈련 담당자 I).

\section{5. 결론 및 제언}

기업교육 분야에서 스마트 훈련의 도입은 기존 교육훈련 방 식에서 탈피한 대안적인 방식을 통해, 학습방법의 변화와 다양 한 요구에 부응하려는 시도의 일환이다. 스마트 시대로 일컬어 
지는 미래 사회에 능동적으로 대응하고자 하는 기업에서는 이른 바 스마트 훈련의 도입을 오래 전부터 고려해왔으나(Kim, Shin, \& Jung, 2013), 더 많은 기업으로의 확산과 혁신적인 시도는 다 소 제한적으로 이루어지고 있는 상황이다. 이에 본 연구에서는 스마트 훈련에 대한 주요 이해관계자의 인식과 현황, 성과, 활성 화를 위한 방안을 확인하였다. 분석 결과를 통해 확인된 요구사 항과 그에 따른 주요 고려사항을 정리해보면 다음과 같다.

첫째, 스마트 훈련 및 스마트 훈련 제도에 대한 이해도를 높이기 위한 노력이 요구된다. 설문을 통하여 기업이 가지고 있는 스마트 훈련에 대한 인식을 살펴본 결과 스마트 훈련이 기존의 훈련방식과 구분하기 어려우며, 이것이 일련의 진입장 벽으로 작용할 수 있음을 확인할 수 있었다. 구체적으로 스마 트라는 정의 자체가 기존의 원격-집체 훈련의 한계를 보완한다 는 점, 유연하다는 점, 혁신적이라는 점 등 어떠한 방향성을 지향하는 것인지 알기 어렵다는 점 등이 지적되었다.

둘째, 제도와 현장 요구간의 불일치 문제에 대한 개선 노력 이 필요하다. 훈련 기관에서 스마트 훈련을 도입하고자 하는 이유는 훈련 성과에 대한 기대, 사업주 및 학습자의 요구, 유 연한 방식으로 훈련 제공이 가능하다는 이유에서였다. 실제로 스마트 훈련을 운영한 경험이 있는 기관을 대상으로 훈련 성 과에 대한 인식을 조사한 결과 학습자 및 고객사 만족도 측면 에서 긍정적인 결과를 확인할 수 있었고, 훈련기관 내부 역량 을 강화하는 데에도 기여하였음을 확인할 수 있었다.

그러나 사업주 및 학습자의 요구가 부족하고, 기대하는 바 와 달리 유연한 방식으로 훈련을 제공하는 것에 어려움이 있 어 스마트 훈련을 전면 확대하는 등의 적극적인 입장을 취하 기는 어려운 것으로 나타났다. 특히나 훈련기관의 재무적 성과 에 기여하는 부분에 대해 상대적으로 낮게 평가하고 있어, 이 미 스마트 훈련 운영경험이 있음에도 불구하고 확대 계획이 전혀 없거나 뚜렷한 계획을 수립하지 못하고 있을 것으로 예 측된다. 훈련 유형별 비교에서 스마트 훈련에 투자되는 시간, 비용 등이 가장 높게 나타났음에도 불구하고, 교육 효과나 학 습자 선호도 측면에서 타 훈련 방식에 비하여 높은 순위를 나 타내지 못하는 결과를 통해서도 이러한 사정을 확인할 수 있 다.

셋째, 스마트 훈련 도입 장애요소 해소방안을 마련할 필요 가 있다. 설문 분석을 통하여 혼합훈련 및 스마트 훈련 도입 과정에서 겪게 되는 여러 가지 장애요소에 대한 확인이 이루 어졌다. 구체적으로 살펴보면 스마트 훈련을 도입하는 과정에 서 투입되는 노력과 투자 대비 얻게 되는 성과가 적다는 판단 을 하고 있는 것이다. 이와 더불어 유연한 방식으로 훈련 제공 이 어렵고, 훈련기관 내부 역량이 부족하다는 점, 과정 심사에 대한 부담감이 크다는 것도 중요한 문제로 지적되었다. 스마트 훈련 활성화를 위해서는 훈련기관 내부 혹은 외부적 차원에서 의 장애요소에 대한 해결방안이 모색될 필요가 있다. 우선 훈 련기관 내부적인 장애요소로는 과정 심사 준비 및 과정 운영 을 위한 내부 역량이 부족하다는 점을 꼽을 수 있다. 활성화 방안에 대한 설문 결과에서도 스마트 훈련 과정설계 관련 전 문성 부족이 활성화 저해요인 중 높은 순위(2순위)를 차지하였 다.

이상의 내용을 토대로 향후 스마트 훈련 도입 및 활성화를 위하여 시도해야 할 것은 다음과 같다.

첫째, 스마트 훈련 활성화를 위해서는 스마트 훈련의 가시 적인 혹은 잠재적인 성과가 무엇인가에 대한 분석이 필요할 것으로 보인다. 이제까지 스마트 훈련과 관련된 학술적인 논의
가 많이 이루어진 것에 비하여, 스마트 훈련의 성과에 대한 실 증적인 연구가 부족했던 상황이다(Kim, Shin, \& Jung, 2013). 성공적인 교육훈련의 성과라고 할 수 있는 기업 구성원들의 수행 증진, 능률성, 학습경험 등에 대한 분석이 이루어져야 할 것이며, 교육훈련의 본질적인 목적을 달성하였는가에 대한 확 인이 필요하다. 이와 더불어 스마트 훈련의 비즈니스 모델에 대한 탐색이 이루어져야 할 것이다(Salehinejad \& Samizadeh, 2017). 즉, 스마트 훈련을 실시하는 데 있어 소요되는 노력에 상응하는 성과 요소는 무엇인가에 대한 분석을 토대로 스마트 훈련 도입에 대한 긍정적인 의사 결정이 이루어질 수 있도록 지원할 필요가 있을 것이다.

둘째, 스마트 훈련에 대한 구체적인 가이드라인, 우수 사례 를 제공하여 스마트 훈련에 대한 이해를 높이고, 스마트 훈련 을 설계하고 운영해나가는 과정에서 지속적인 도움을 받을 수 있도록 컨설팅 지원 혹은 스마트 훈련에 대한 교육 프로그램 을 제공할 필요가 있다. 스마트 훈련이 기존의 원격훈련, 집체 훈련과 어떠한 차이가 있는지, 어떠한 가치를 지향하는지에 대 한 인식이 공유되고, 공감대가 형성되기 전까지는 스마트 훈련 의 활성화가 이루어지기 어렵다. 스마트 훈련을 선도적으로 도 입한 기업을 중심으로 구체적인 도입 전략을 소개할 수 있는 기회를 마련하고, 스마트 훈련 도입 과정에서 경험한 어려움과 극복방안, 새롭게 시도하고자 하는 전략 등을 전파할 경우, 새 로운 시도로 인해 발생할 수 있는 초기 부담감과 혼란을 최소 화할 수 있을 것이다. 또한 사업주 및 학습자 입장에서 스마트 훈련에의 참여가 용이할 수 있도록 교육 운영 시 고려할 요소 에 대한 추가적인 분석이 요구된다.

셋째, 사업주 및 학습자들의 관심을 모을 수 있도록 스마트 훈련의 이점에 대한 홍보 및 교육 참여에의 유인책을 마련할 필요가 있다. 유인책은 비용적, 물리적 지원만을 의미하는 것 이 아니라 스마트 훈련의 도입을 긍정적으로 고려할 수 있는 근거를 마련하는 일이 중요하다. Sim and $\operatorname{Lim}(2013)$ 에 따르면 스마트 훈련의 자기주도성, 콘텐츠 품질, 상호작용성 등이 훈 련 성과에 긍정적인 영향을 미치는 것으로 나타났다. 또한 스 마트 훈련 운영 결과 이러한 스마트 훈련의 특성이 기업에서 의 교육훈련을 통해 추구하는 학습전이와 훈련생들의 만족도 에 기여함을 확인할 수 있었다. 향후 현업 적용도나 업무몰입 도 등 기업의 교육훈련에서 기대하는 성과를 기존의 훈련 방 식과 비교하여 어느 정도로 달성하는가에 대한 연구 등 검증 이 이루어질 필요가 있다.

넷째, 스마트 훈련 활성화를 위한 제도적 지원이 요구된다. 스마트 훈련 활성화를 위해서 가장 필요한 요소에 대하여 훈 련 담당자들은 과정 설계, 운영, 평가 자율성을 최대한 인정해 줄 것, 심사과정을 간소화하는 것이 중요하다는 의견이 가장 많았다. 설문 결과에 따르면 스마트 훈련에 대하여 기관 입장 에서는 유연한 과정 운영이 가능하다는 점을 가장 크게 인식 하고 있었던 반면, 정작 기대와는 달리 유연성이 확보되지 못 하고 있다는 불만이 있었다. 스마트 훈련에 대한 비용 인정 폭 이 크고, 심사 통과 기관의 사례가 우수사례로 인식될 가능성 이 큰 만큼 심사 과정에서 엄정성을 기울여야 하는 것은 분명 하나, 훈련기관의 의도와 운영상의 맥락을 이해하고, 최적의 교수 전략 및 교육적 성과를 높일 수 있는 방향성을 제안하는 컨설팅의 차원에서 심사가 이루어졌을 때 기관의 적극적인 참 여를 유도할 수 있을 것으로 본다. 


\section{References}

Choi, H. S., Woo, Y. H., \& Jung, H. J. (2013). Students' Perception of Smart Learning in Distance Higher Education. Korea Contents Association Thesis Journal, 13(10), 584-593.

Jung, H. J. (2017). A Study on the Strategies of Developing e-Learning Contents for Adult Learners. Journal of Learner-Centered Curriculum and Instruction, 17(4), 587-608.

Jung, H. J. (2018). Trends and Future Directions of Corporate e-learning Contents. The Journal of Industrial Distribution \& Business, 9(2), 65-72.

Kim, Y. (2017). A Study on e-learning Contents Opening Information for Distribution Industry Labor Competence. Journal of Distribution Science, 15, 65-73.

Kim, H. Y., Shin, W. S., \& Jung, J. W. (2013). Analysis of Factors Influencing Learners' Satisfaction and Intention of Smart Learning System in Organizational Learning Context. Journal of Korean HRD Research, 8(4), 27-49.

Salehi, M., Zadeh, F. N., Saei, M. J., \& Rostami, V. (2013). Reforming Accounting Education Content to Fulfill Business Environment Needs. The Journal of Industrial Distribution \& Business, 4(2), 5-11.

Salehinejad, A., \& Samizadeh, R. (2017). A Conceptual Framework for Determination of Appropriate Business Model in e-Learning Industry in Iran. The East Asian Journal of Business Management, 7(4), 17-25.

Sim, H. S., \& Lim, H. S. (2013). A study on the effectiveness of smart learning in education training. Journal of Cyber Education, $7(2)$, 139-160. 